\title{
Highly uniform and reproducible visible to near-infrared vertical-cavity surface-emitting lasers grown by MOVPE
}

\author{
H. Q. Hou, K. D. Choquette, B. E. Hammons, W. G. Breiland, \\ M. H. Crawford, and K. L. Lear, \\ Center for Compound Semiconductor Technology \\ Sandia National Laboratories, MS 0603, Albuquerque, NM 87185, U.S.A. PA.M 197 \\ OST
}

\begin{abstract}
We present the growth and characterization of vertical-cavity surface emitting lasers (VCSELs) from visible to near-infrared wavelength grown by metalorganic vapor phase epitaxy. Discussions on the growth issue of VCSEL materials include the control on growth rate and composition using an in situ normalincidence reflectometer, optimization of ultra-high material uniformity, and comprehensive $p$ - and $n$-type doping study in $\mathrm{AlGaAs}_{\mathrm{G}}$ by $\mathrm{CCl}_{4}$ and $\mathrm{Si}_{2} \mathrm{H}_{6}$ over the entire $\mathrm{Al}$ composition range. We will also demonstrate our recent achievements of selectively-oxidized VCSELs which include the first room-temperature continuous-wave demonstration of all-AlGaAs 700-nm red VCSELs, high-performance $n$-side up $850-\mathrm{nm}$ VCSELs, and low threshold current and low-threshold voltage $1.06 \mu \mathrm{m}$ VCSELs using InGaAs/GaAsP strain-compensated quantum wells.
\end{abstract}

Keywords: vertical-cavity surface-emitting lasers, metalorganic vapor phase epitaxy, reflectometry.

\section{INTRODUCTION}

Vertical-cavity surface emitting lasers (VCSELs) are promising for a variety of applications such as optical interconnects and communications, laser printing, recording, and displays. ${ }^{1}$ The growth of VCSEL structures, however, is very demanding. The thickness and composition control has to be accurate enough to align the mirror reflectance wavelengths of the top and bottom distributed Bragg reflectors (DBRs), the gain spectrum, and cavity resonance wavelength to a specific wavelength regime. In addition, the composition and doping level across the interfaces of the high- and low-index DBR constituents often need to be graded continuously to reduce the device series resistance. Metalorganic vapor phase epitaxy (MOVPE) technology appears to be a superior growth platform because of the ability to accomplish these with high throughput. However, the control of the composition, layer thickness, and doping level can be complicated. In this paper, we will present the critical issues and optimization for growth of high-quality VCSEL materials, and demonstrate some recent results of VCSELs from red $(\sim 700 \mathrm{~nm})$ to near-infrared $(\sim 1.1 \mu \mathrm{m})$ wavelength.

\section{GROWTH OF VCSELS}

Epitaxial growth was performed in an EMCORE GS3200 MOVPE rotating disk reactor. GaAs and $\mathrm{Al}_{x} \mathrm{Ga}_{1-x} \mathrm{As}$ were grown at $750^{\circ} \mathrm{C}$ by using trimethylgallium (TMG), trimethylaluminum (TMA), and $100 \%$ arsine $\left(\mathrm{AsH}_{3}\right)$. InGaAs and $\mathrm{GaAsP}$ were grown at $620^{\circ} \mathrm{C}$ by using trimethylindium (TMI), TMG, $\mathrm{AsH}_{3}$ and $100 \%$ pure phosphine $\left(\mathrm{PH}_{3}\right)$. Dopants for $n$ - and $p$-type materials were from disilane $\left(\mathrm{Si}_{2} \mathrm{H}_{6}\right)$ and carbon-tetrachloride $\left(\mathrm{CCl}_{4}\right)$, respectively. The alkyl and doping precursors were mixed in an injection 
block, and carried by high-purity $\mathrm{H}_{2}$ to the EMCORE vertical reactor through 3 different injection zones distributed along the radial direction on the top flow-injection flange. The $\mathrm{AsH}_{3}$ was injected through two other zones. The reactants were isolated from the stainless steel chamber wall with a high hydrogen flow along the shroud. Therefore, there is little up-stream contamination or carryover to a substrate. The substrate was rotated at $1000 \mathrm{rpm}$. The reactor pressure was 60 torr.

\subsection{Growth rate and composition determination by in situ reflectometry}

In the past, the versatility of the MOVPE technology has been compromised due to the lack of a suitable in situ pregrowth calibration tool. The traditional geometry of the MOVPE reactor prohibits the use of in situ tools, such as pyrometric interferometry and ellipsometry, which are commonly used in a molecular beam epitaxy (MBE) system for growth monitoring. Slight day-to-day variation can drift the VCSEL wavelength and change the laser characteristics significantly since the control of growth rate, composition, and doping are so critical for VCSELs. The MOVPE growth conditions are usually determined in advance through an often tedious set of calibration runs. We employed an in situ technique by normal-incidence reflectometry for pregrowth growth-rate and composition calibration and real-time growth monitoring.

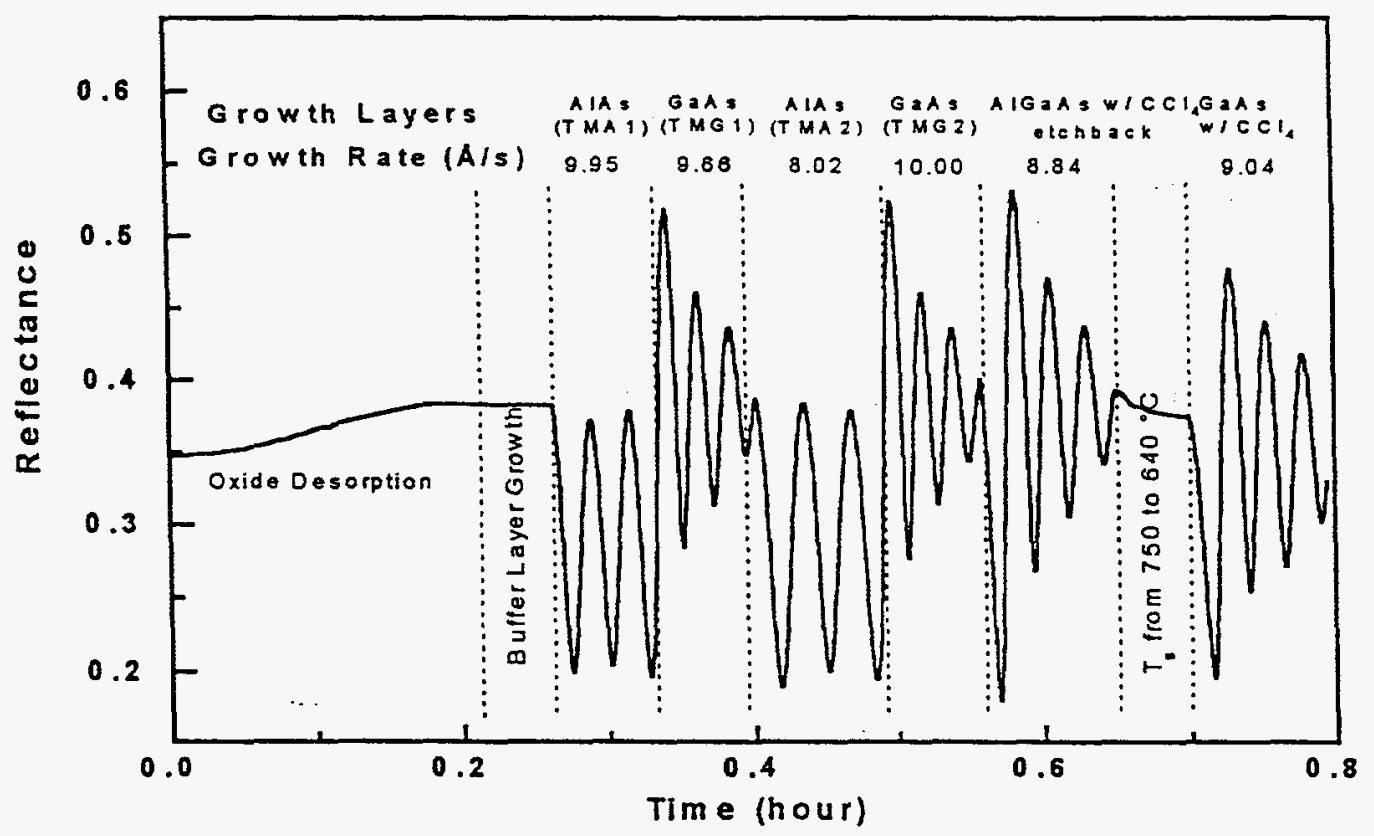

Fig. 1. Temporal reflectance of a typical calibration run for the growth rate and etchback rate during AlGaAs growth. The alloy composition can be linearly interpolated. Within an hour, growth and etchback rates are obtained for the various growth conditions.

The normal-incidence reflectance setup consists of a 7-watt W-halogen lamp as the light source and a silicon detector with a $10 \mathrm{~nm}$ bandwidth interference filter at $633 \mathrm{~nm}$ to detect the reflectance signal. The whole assembly was mounted directly on the top miniflange window of the reactor. A virtual interface model $^{2}$ extracts the growth rate and optical constants from the absolute reflectance of only the topmost layer by referencing the starting signal to the known reflectance of the substrate before epitaxy begins. It does not require any knowledge of epitaxial materials, interface position, thickness, or composition of underlying epitaxial layers. This provides a simple, robust, and accurate measurement of the growth rate. ${ }^{3}$ 


\section{DISCLAIMER}

This report was prepared as an account of work sponsored by an agency of the United States Government. Neither the United States Government nor any agency thereof, nor any of their employees, makes any warranty, express or implied, or assumes any legal liability or responsibility for the accuracy, completeness, or usefulness of any information, apparatus, product, or process disclosed, or represents that its use would not infringe privately owned rights. Reference herein to any specific commercial product, process, or service by trade name, trademark, manufacturer, or otherwise does not necessarily constitute or imply its endorsement, recommendation, or favoring by the United States Government or any agency thereof. The views and opinions of authors expressed herein do not necessarily state or reflect those of the United States Government or any agency thereof. 



\section{DISCLAMMER}

Portions of this document may be illegible in electronic image products. Images are produced from the best available original document. 

Shown in Fig. 1 is the temporal reflectance from a typical calibration run. The growth rates achieved by using various alkyl sources were determined from fitting the reflectance waveform with the virtual interface model. The alloy composition can be linearly interpolated since the growth rate is mass transport limited in most of the growth conditions. The reduction of the growth rate due to an etchback effect of AlGaAs and $\mathrm{GaAs}$ by $\mathrm{CCl}_{4}$ with different $\mathrm{C}$ doping levels at different temperatures is also extracted from this single calibration run of less than an hour. ${ }^{3}$ The small deviation of the growth rate from the expected value is therefore corrected according to the calibration.

This in situ technique provides a quick and accurate pre-growth calibration for growth rates. It has also been used as a real-time growth status monitor because of its non-intrusive nature. Shown in Fig. 2 is a reflectance curve for a typical VCSEL run. The signatures for different layers of the VCSEL can be clearly identified. If any unusual occurrences happen, for instance, running out of source materials, lattice mismatching, improper growth procedures, and so on, the problem can be quickly detected by comparing the refiectance curve with a similar material structure which is known to be good. This has greatly simplified the post-growth failure analysis process.

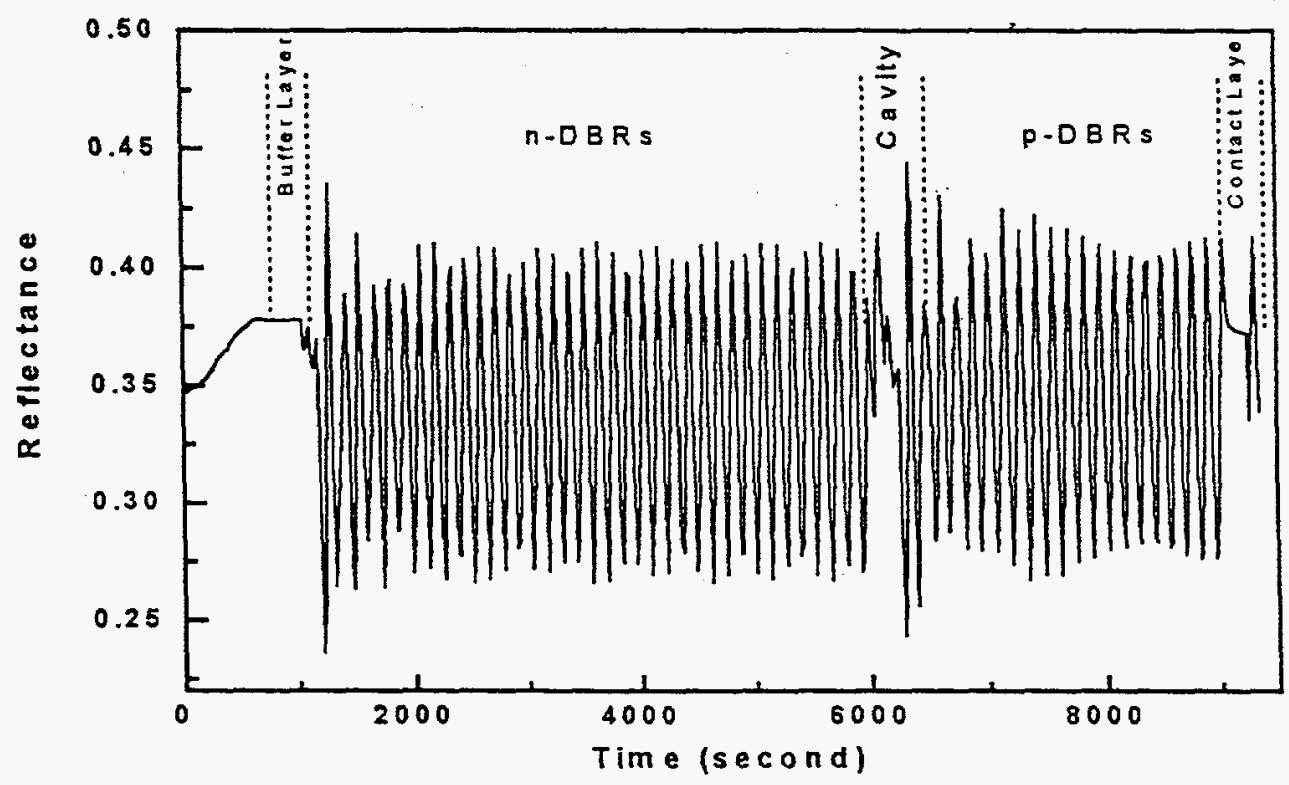

Fig. 2 A reflectance curve for a typical 850-nm VCSEL run. In situ reflectance is used routinely to monitor the growth in real time. Different parts of the VCSEL structure can be clearly identified.

\subsection{Carbon doping and etchback effect in AlGaAs}

One of the critical growth issues is to dope DBRs just enough to achieve low series resistance and also keep the free-carrier absorption low. Carbon is a very attractive $p$-type dopant for GaAs and AlGaAs due to its low activation energy, good electrical activity, low diffusivity, and high solid solubility. ${ }^{4}$ However, the utilization of $\mathrm{CCl}_{4}$ as a doping source brings parasitic etching reactions by $\mathrm{Cl}$ radicals which reduce the growth rate. We have performed an extensive study of the $\mathrm{C}$ doping efficiency by $\mathrm{CCl}_{4}$ in AlGaAs over the entire range of $\mathrm{Al}$ composition. Shown in Fig. 3 is the carrier concentration and etchback rate as a function of the $\mathrm{CCl}_{4}$ partial pressure in $\mathrm{GaAs}$ at $630^{\circ} \mathrm{C}$. The free carrier concentration from Hall measurements is almost linearly dependent on the flow rate or partial pressure of the $\mathrm{CCl}_{4}$. This implies that there is no self-compensation process in C doping. A large dynamic range from $10^{16}$ to high $10^{19} \mathrm{~cm}^{-3}$ doping can be achieved routinely with excellent surface morphology at this temperature. A higher doping level can be obtained by using a higher $\mathrm{CCl}_{4}$ partial pressure at a lower growth temperature. 
The etchback rate as measured from the in situ reflectance ${ }^{3}$ is the difference of the growth rates when the film was grown with the $\mathrm{C}$ doping and without the $\mathrm{C}$-doping. This is plotted in Fig. 3 on the right $\mathrm{y}$-axis during GaAs growth at $630^{\circ} \mathrm{C}$. The etchback rate is almost proportional to the $\mathrm{CCl}_{4}$ partial pressure. This linear etchback rate dependence on the $\mathrm{CCl}_{4}$ partial pressure implies a reactant limited etching process.

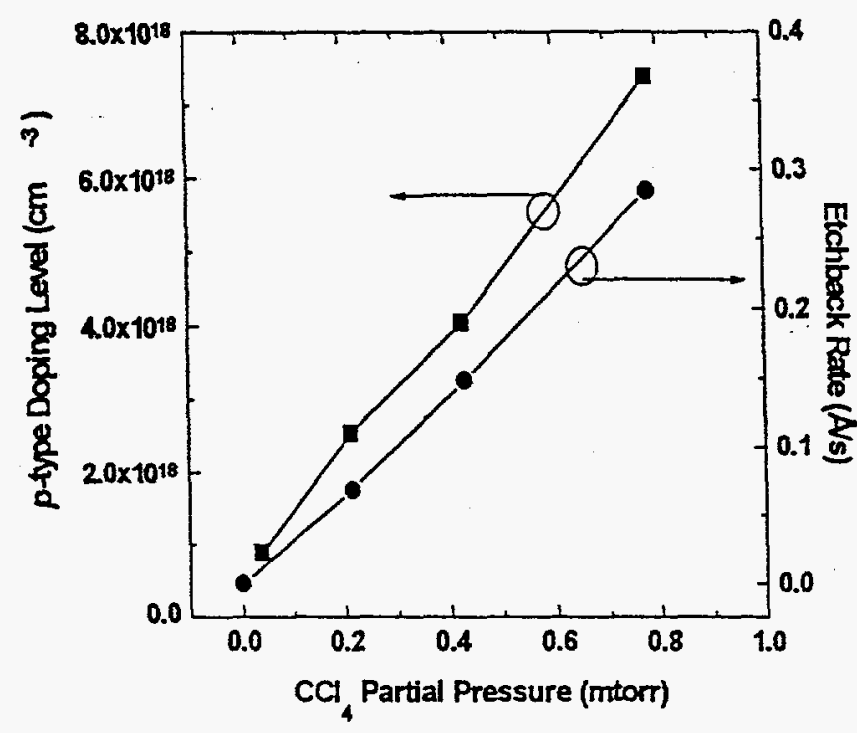

Fig. 3 Carrier concentration and etching rate in $\mathrm{GaAs}$ at $630^{\circ} \mathrm{C}$ as a function of the $\mathrm{CCl}_{4}$ partial pressure.

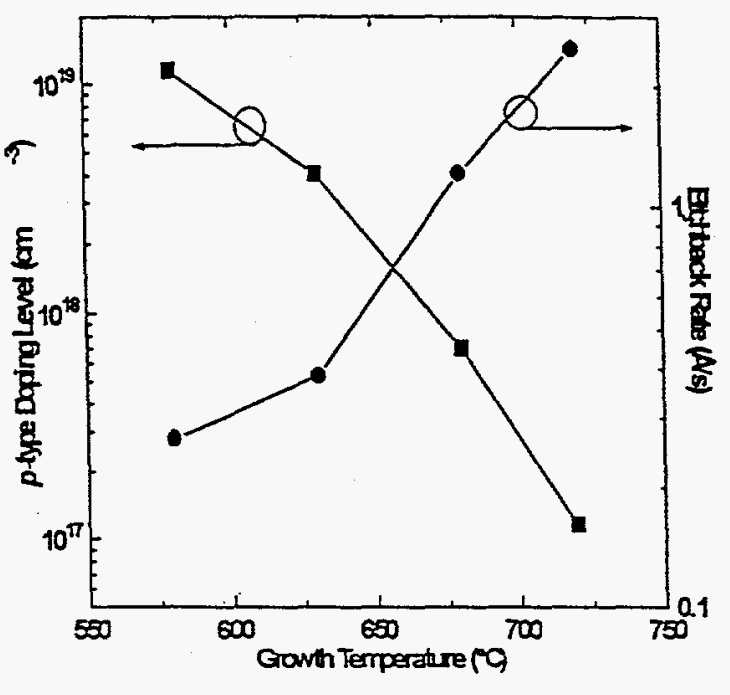

Fig. 4 Carrier concentration and etching rate in GaAs as a function of the growth temperature.

We also found a strong dependence of the doping efficiency and etchback rate on the growth temperature. Figure 4 shows the carrier concentration and etching rate as a function of the growth temperature for $\mathrm{GaAs}$ with a fixed $\mathrm{CCl}_{4}$ partial pressure of 0.43 mtorr. When the growth temperature varies from 580 to $720^{\circ} \mathrm{C}$, the doping efficiency decreases by two orders of magnitude as shown by the left $y$-axis, and the etching rate increases by an order of magnitude as shown by the right $y$-axis in Fig. 4 . Therefore, higher carrier concentration can be more readily achieved at a lower growth temperature where the etchback rate is much slower. Another noteworthy feature shown in Fig. 4 is that the doping level can change by 30 to $40 \%$ if the growth temperature varies $20^{\circ} \mathrm{C}$. Therefore, a uniform growth temperature across the substrate is essential for achieving a uniform $p$-type carrier concentration.

The $\mathrm{CCl}_{4}$ doping and etchback behaviors were also studied for AlGaAs with aluminum compositions ranging from 0 to 1 while the same $\mathrm{CCl}_{4}$ flow rate or partial pressure is maintained. ${ }^{5}$ As shown in the Fig. 5, the carrier concentration changes from $2 \times 10^{17}$ to $2 \times 10^{19} \mathrm{~cm}^{-3}$ at a partial pressure of 0.275 mtorr and growth temperature of $720^{\circ} \mathrm{C}$ when the $\mathrm{Al}$ composition in $\mathrm{AlGaAs}$ changes from 0 to 1 . Therefore, the $\mathrm{CCl}_{4}$ flow rate has to be varied accordingly to achieve a constant doping level in $\mathrm{Al}_{x} \mathrm{Ga}_{1-x} \mathrm{As}$. Furthermore, the right $\mathrm{y}$-axis in Figure 5 shows that the etchback rate has a strong dependence on the Al composition in the AlGaAs. The etchback rate for GaAs is approximately 15 times higher than that for AlAs. The curves through data points are fits using multiple exponential functions which are used to change the $\mathrm{CCl}_{4}$ flow rate for a desired doping level, or to calculate the etch rate at a given $\mathrm{Al}$ composition. The etching rate selectivity versus $\mathrm{Al}$ composition in $\mathrm{AlGaAs}$ has a direct implication for in situ surface processing and regrowth. It can be used in a process where GaAs is selectively etched away from a patterned heterostructure, and then an in-fill regrowth can be followed immediately in the reactor. The regrown heterostructure will then provide another degree of carrier, optical, and electrical confinement in the lateral direction for a novel device structure. ${ }^{5}$ 

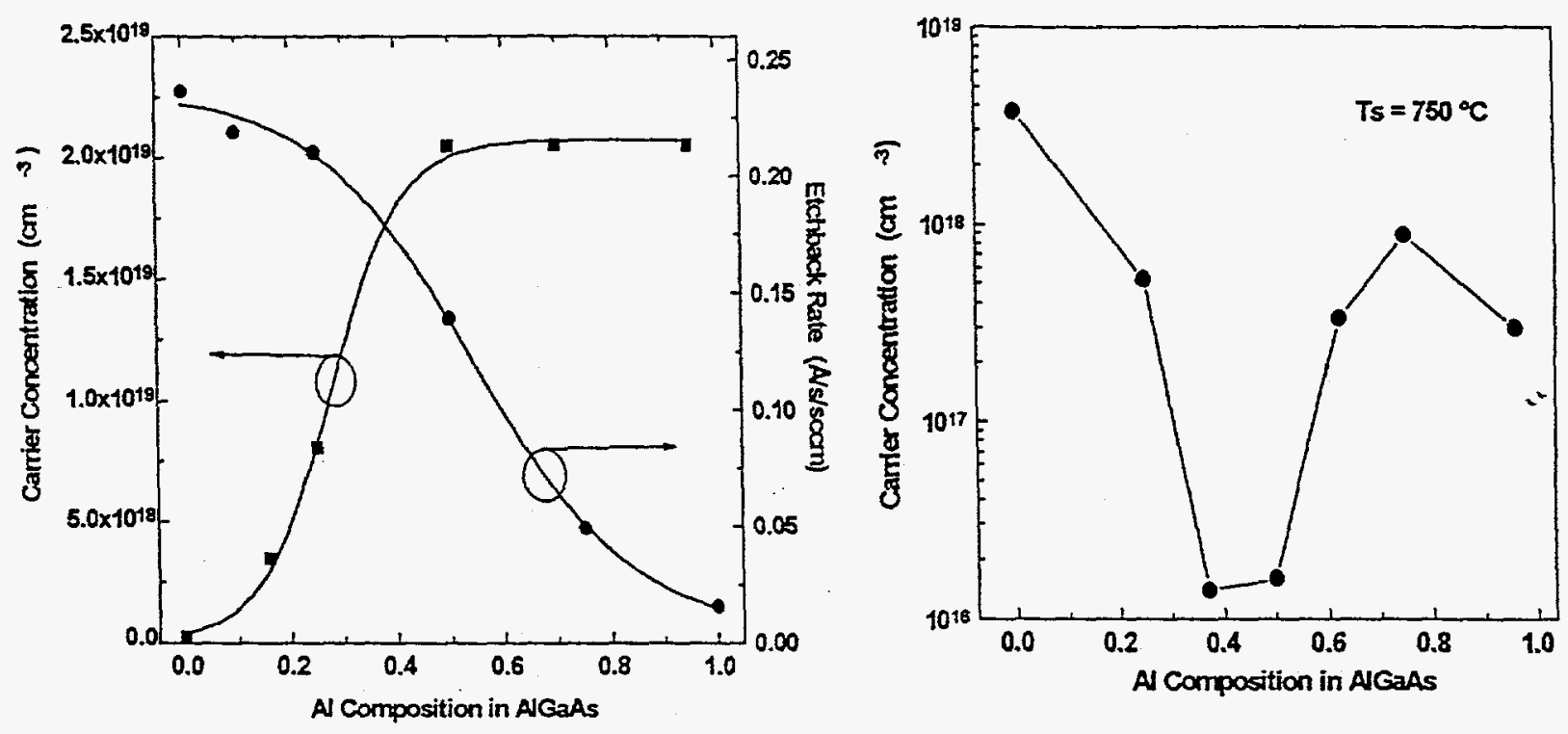

Fig. 5 Carrier concentration and etching rate for $\mathrm{AlGaAs}$ with different $\mathrm{Al}$ composition when the $\mathrm{CCl}_{4}$ flow rate is kept the same.

Fig. 6 Free carrier concentration in Si-doped AlGaAs grown at $750^{\circ} \mathrm{C}$ as a function of the $\mathrm{Al}$ composition when the $\mathrm{Si}_{2} \mathrm{H}_{6}$ flow is kept the same.

The doping and etching behavior as discussed above can be understood as follows. As a $p$-type dopant, carbon is incorporated into the As site in $\mathrm{AlGaAs}$. However, the $\mathrm{Cl}$ may react with $\mathrm{Ga}$ or $\mathrm{Al}$ atoms on the surface, and form volatile $\mathrm{GaCl}_{3}$ or $\mathrm{AlCl}_{3}$. This will in turn reduce the probability of the $\mathrm{C}$ to be bonded with $\mathrm{Ga}$ or $\mathrm{Al}$ atoms, therefore, lowering the doping efficiency. Thus, faster etchback and less efficient doping result from the same mechanism. The higher the $\mathrm{CCl}_{4}$ flow, the faster the etchback rate. Since such a reaction between $\mathrm{Cl}$ and $\mathrm{Ga}(\mathrm{Al})$ is expected to be more significant at higher temperature, this will lead to a faster etchback rate and inefficient $C$ doping as we see from the experiment. Furthermore, $\mathrm{AlCl}_{3}$ is less volatile than $\mathrm{GaCl}_{3}$, and the $\mathrm{Al}-\mathrm{C}$ bond energy $(65 \mathrm{kcal} / \mathrm{mol})$ is larger than $\mathrm{Ga}-\mathrm{C}$ bond (59 $\mathrm{kcal} / \mathrm{mol}$ ). Therefore, the etchback rate will be slower for AlAs than for GaAs, and the $\mathrm{C}$ can be more readily doped into AlAs than GaAs. This accounts for the strong dependence of the doping level and etchback rate on the Al composition in AlGaAs.

\subsection{Silicon as an n-type dopant in AlGaAs}

The $n$-type doping in AlGaAs was achieved with $\mathrm{Si}_{2} \mathrm{H}_{6}$. It is found that the $\mathrm{Si}$ doping efficiency is not very temperature dependent in the growth temperature range from 640 to $750^{\circ} \mathrm{C}$. Figure 6 shows the carrier concentration from Hall measurements as a function of the Al composition in AlGaAs which was all doped with $\mathrm{Si}_{2} \mathrm{H}_{6}$ at a flow of $0.73 \mathrm{sccm}$. The free carrier concentration in $\mathrm{GaAs}$ is approximately 4 times higher than in AlAs, and a drop of two orders of magnitude occurs at an Al composition of about 0.45 . On the other hand, the Polaron measurements showed the same doping concentration of $\mathrm{Si}$ in AlGaAs in the entire composition range. Therefore, the low carrier concentration in the vicinity of $x=0.45$ is due to insufficient activation. This drop can be well correlated to a sudden increase of the activation energy of $\mathrm{Si}$ in AlGaAs with $x \sim 0.45$, which is due to the transition of the conduction bandedge of AlGaAs from direct to indirect around this composition range. ${ }^{6}$ Furthermore, the conduction bandedge transition from $\Gamma$ to $\mathrm{X}$ band gives rise to an increase of the electron effective mass, which results in a deficient activation of the $n$ - 
type dopant. An attempt to increase the doping concentration may not lead to an increase of free carrier concentration, since the Si dopant can be substitutional but not activated or interstitial. The presence of a large concentration of interstitials, however, should produce significant outdiffusion during post-growth processing and device operation. This may cause device reliability problems. Therefore, a mirror design which skips the Al composition range of insufficient $n$-dopant activation should be beneficial to a reliable low-series resistance. ${ }^{7}$

\section{MATERIAL UNIFORMITY}

The sample uniformity was optimized by changing the gas-flow partition for alkyl sources among the three injection zones with the hydride flow partition of $80 \%: 20 \%$ between the inner and outer injection zones and a total reactor flow of $32.6 \mathrm{sm}$. Mirror structures of 20-period AlGaAs/AlAs DBRs were grown under different conditions. The center wavelength of the DBR reflectivity stopband was measured for different radial positions of a 3" diameter wafer. It is found that equal alkyl distribution among the three injection zones on the top flange did not give a uniform growth rate on the substrate. Instead, a setting of the gas-flow distribution of 7\%:78\%:15\% between the inner, middle, and outer injection zones yielded the most uniform thickness. The uniformity, which is most sensitive to the partition setting, was further optimized with the $\mathrm{AsH}_{3}$ flow rate, or the V/III ratio. We found that the uniformity can be tuned slightly with $\mathrm{AsH}_{3}$ flow rates from 230 to $270 \mathrm{sccm}$, or the equivalent V/II ratio from 36 to 42.3 , and the best uniformity across an entire 3" wafer was achieved with an $\mathrm{AsH}_{3}$ flow of $248.5 \mathrm{sccm}$, or a V/III ratio of approximately 39 .

Figure 7 shows the wavelength of the Fabry-Perot cavity mode for an 840-nm VCSEL structure grown with the above-optimized conditions as a function of the distance from the wafer center. The uniformity was found to be rotation symmetric except for a little disturbance near the major flat of the wafer. The wavelength for the area $\sim 3 \mathrm{~mm}$ from the wafer edge (the last data point in Fig. 7) can be slightly influenced by the thickness of material coated on the susceptor. The wavelength variation $(\Delta \lambda)$ was measured to be $0.8 \mathrm{~nm}$ in the center 2" and $3.3 \mathrm{~nm}$ across the entire 3 "wafer. This corresponds to a wavelength uniformity of $\pm 0.05 \%$ in the center 2 " area of the 3 "wafer, and $\pm 0.2 \%$ over the entire 3 " wafer. ${ }^{8}$

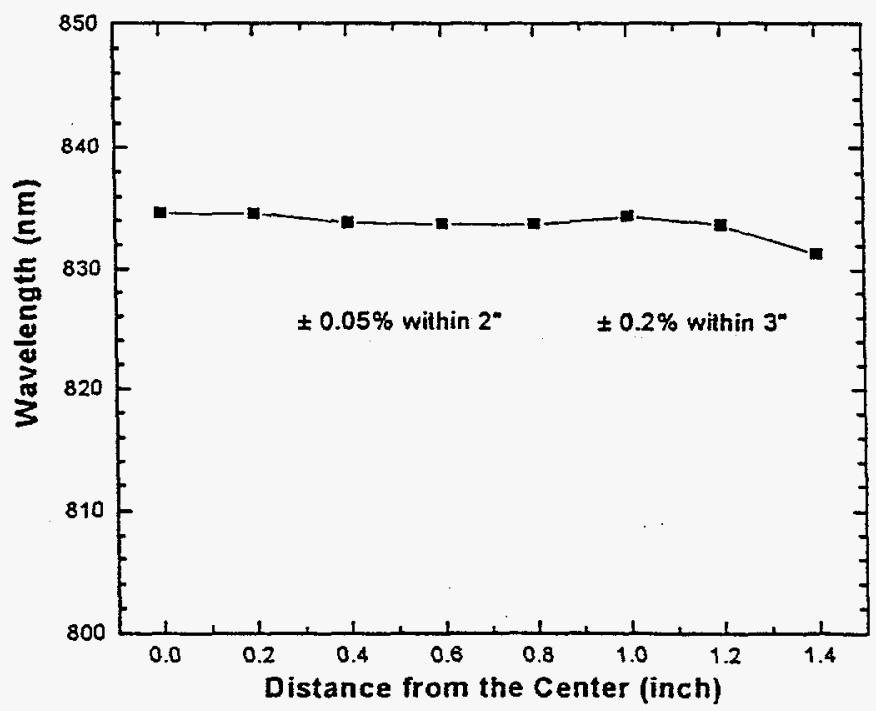

Fig. 7. Wavelength of the Fabry-Perot cavity mode for an 850-nm VCSEL as a function of the distance from the wafer center. 
The uniformity of the wavelength indicates a uniformity of the optical thickness which is the product of the physical thickness and the optical constant, a function of the alloy composition. Since the alkyl gases are mixed uniformly before being injected into the reactor, and the incorporation ratio of $A 1 / G a$ is fairly insensitive to a small temperature variation around $750^{\circ} \mathrm{C}$, the composition variation across a wafer should be negligible. We have verified this by mapping the wafer with $\mathrm{x}$-ray rocking curves. Shown in Figure 8(a) are six x-ray diffraction curves from a 20-period DBR sample measured at different positions from the center. They are nearly identical. Figure $8(\mathrm{~b})$ shows the angular separation between the substrate Bragg angle and the zeroth-order satellite peak, $\Delta \theta_{\mathrm{B}}$, which is a measure of the Al composition in the AlGaAs layer, and between the adjacent satellite peaks, $\Delta \theta_{0,1}$, which is a measure of the total layer thickness within one period. The variations for both $\Delta \theta_{B}$ and $\Delta \theta_{0,1}$, are within the experimental uncertainty, \pm 2 arc seconds. This indicates that both the thickness and composition of the DBR over a 3 " diameter wafer are extremely uniform. Noncontact resistivity mapping for an $n$-doped layer indicates a uniformity of better than $1.5 \%$ over an entire 3" wafer. However, the uniformity of C-doped p-layers depends on the temperature uniformity, resulting from either the heater or the emisivity change due to different coating on the susceptor. A uniformity of better than $2 \%$ can be achieved.

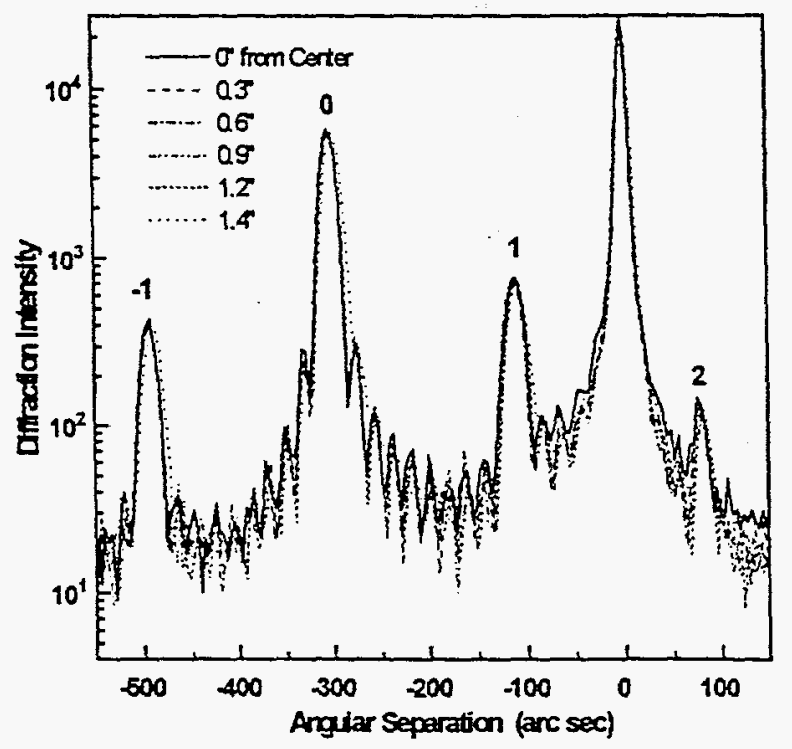

Fig. 8(a) X-ray rocking curves for a 20-period AlGaAs/AlAs DBR taken at different radial positions of a 3 "wafer.

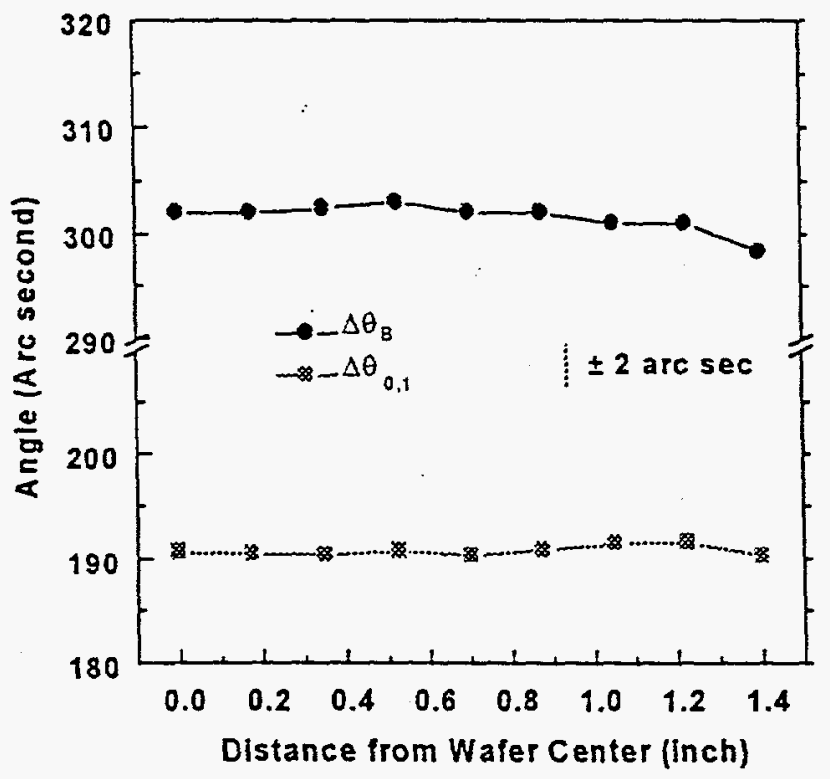

Fig. 8(b) Angular separation between Bragg angles $\left(\Delta \theta_{B}\right)$ and satellite peaks $\left(\Delta \theta_{0,1}\right)$ at different radial positions of a 3 " wafer.

\section{RUN-TO-RUN REPRODUCIBILITY WITH REFLECTOMETRY}

It is very common that the reactor growth parameters such as the growth pressure, growth temperature, bubbler temperature, bubbler pressure, mass flow controller settings, and so on, drift around with time. Therefore, frequent calibrations for the state of the reactor in terms of growth rate, composition, and doping levels should be done. Figure 9 shows the deviation of the flow rates to achieve a growth rate of $10 \AA / s$ for two TMG and TMA sources as a function of the run numbers over a course of $\sim 600$ runs in about 7 8 months period of time. The data are from all the in situ reflectance calibration runs. Note that these drifts are due to all the machine state parameter changes. Although the flow rate deviation can be as high as $\pm 15 \%$ over this long period of time, this state-of-the-art MOVPE reactor is very stable during a short time (e.g., within 30 runs). Since the in situ reflectance calibration is quick and accurate, we have 
implemented periodic pregrowth calibration runs by reflectometry. The drifts of the machine states are detected and adjusted accordingly. Figure 10 shows the cavity wavelengths for a number of 770 - and 850$\mathrm{nm}$ VCSELs plotted as a function of the nun number. The cavity was not changed from run to run for the $770-$ and $850-\mathrm{nm}$ VCSELs, but the mirror design (number of periods and doping concentration) was varied for a structure-design optimization process. Twelve 850-nm VCSELs (run number 1068 to 1073, 1114, and 1163 to 1167) and seven 770-nm VCSELs (nun number 1112 to 1113 and 1115 to 1119) were grown at different times over the course of about 100 runs. Other materials and device structures were grown in between. To ensure reproducibility, a calibration run as shown in Fig. 1 was carried out before a series of VCSELs were grown. Slight changes in the flow rate calibration were made accordingly. As shown in Fig. 10 , we obtained wavelength run-to-run reproducibility of $\pm 0.3 \%$ for both 770 - and 850 -nm VCSELs. Since the calibration included a wide range of composition and doping levels, ${ }^{3}$ reproducible results were achieved in spite of the varying device structures.

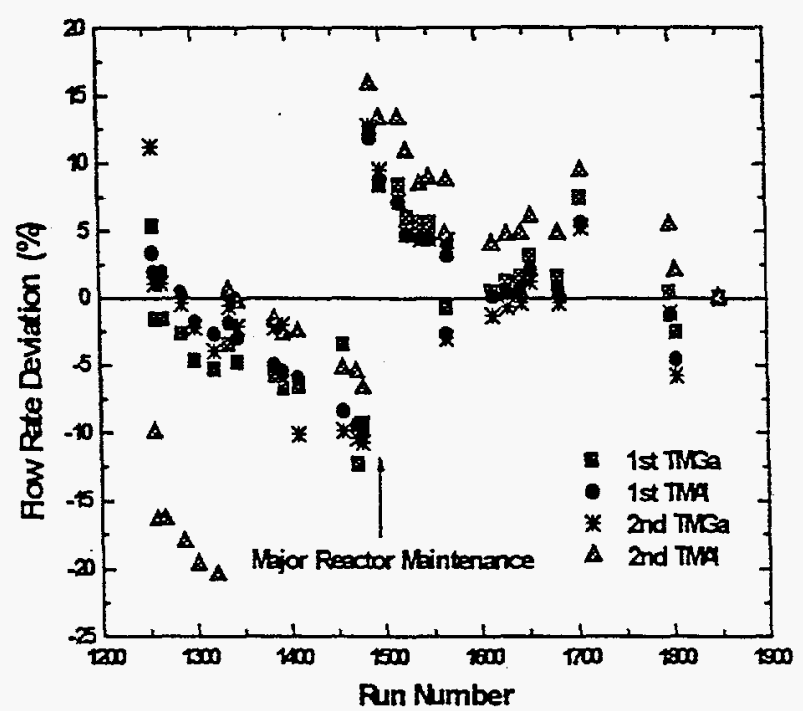

Fig. 9 Flow rate deviation of multiple metalorganic sources for achieving a $10 \AA / \mathrm{s}$ growth rate over $\sim 600$ runs.

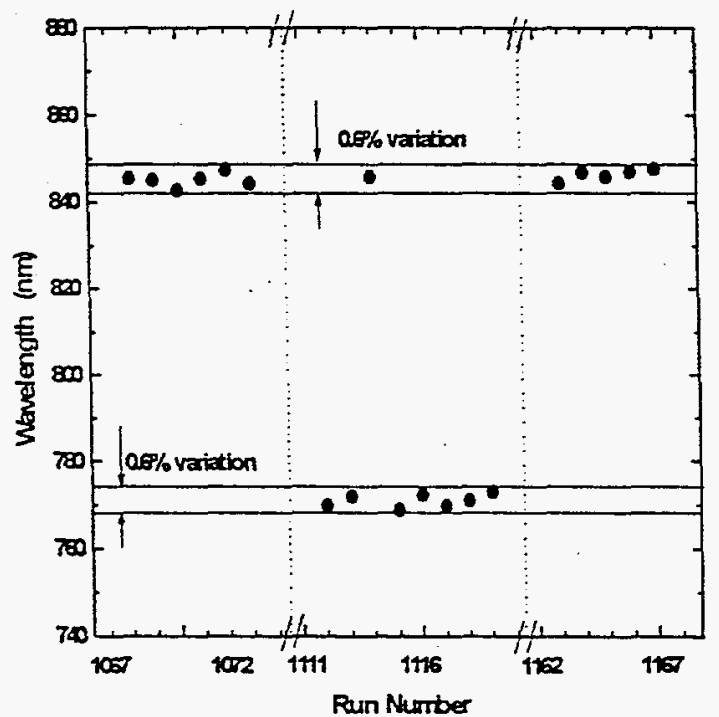

Fig. 10 Reproducibility of the cavity wavelength of 770- and 850-nm VCSEL structures versus the growth run number.

\section{RECENT VCSEL DEVICE RESULTS}

A typical VCSEL sample consists of Si-doped $n$-DBR mirrors with high reflectivity, one-wave thick optical cavity composed of cladding layers with linear composition and doping ramping and quantum well active region, and C-doped $p$-DBR mirrors. A half-wave thick highly-doped $\left(-3 \times 10^{19} \mathrm{~cm}^{-3}\right)$ current spreading layer caps the whole structure. In the DBR layers, the composition was parabolically graded across the interfaces of high and low Al-containing layers to reduce the series resistance. The doping profile in the DBR mirrors was optimized based on the $p$ - and $n$-type doping studies. We have performed a simple one-dimensional Possion-Schrödinger equation to calculate the band diagram. It is found that the energy spike at the heterointerface can be reduced significantly by employing a parabolic composition ramping. As a result, the series resistance is greatly reduced compared to an abrupt and piece-linear ramping profile of the DBR interfaces. ${ }^{7}$ A further improvement can be achieved by modulating the doping profile to compensate for the band bending.

The standard procedures for device isolation include etched air post and proton-implantation. Recently, the process of selective oxidation yielded a significant improvement for device performance. 
AlGaAs with high $\mathrm{Al}$ composition can be converted to a stable oxide, and the oxidation rate of AlGaAs in a hot steam ambient is very dependent on the $\mathrm{Al}$ composition. For instance, the oxidation rate of $\mathrm{Al}_{0.98} \mathrm{Ga}_{0.02} \mathrm{As}$ is 3.5 times higher than $\mathrm{Al}_{0.92} \mathrm{Ga}_{0.08} \mathrm{As}$. ${ }^{9}$ Therefore, if the low-index layer of a DBR mirror contains $\mathrm{Al}_{0.92} \mathrm{Ga}_{0.08} \mathrm{As}$ for most of the $\mathrm{DBR}$ structure, and only leaves one period of $\mathrm{Al}_{0.98} \mathrm{Ga}_{0.02} \mathrm{As}$ layer close to the cavity, this layer can be selectively oxidized to form a current aperture. The typical oxidation rate for $\mathrm{Al}_{0.98} \mathrm{Ga}_{0.02} \mathrm{As}$ layers is approximately $0.8 \mu \mathrm{m} / \mathrm{min}$ at $440^{\circ} \mathrm{C}$. The size of the devices can be easily controlled by the oxidation depth from the side.

\subsection{High-performance n-side up $850 \mathrm{~nm}$ VCSELs}

The most typical Si driving circuit for VCSELs is currently using the npn bipolar-junction transistor. An $n$-side up VCSEL offers a compatible electrical polarity with these drivers, and is very desirable for circuit applications. Figure 11 shows typical output power-current (L-I) and voltage-current (V-I) curves from a room-temperature continuous-wave (CW) 850-nm VCSEL. The device contains 5 $\mathrm{GaAs}(80 \AA) / \mathrm{Al}_{0.2} \mathrm{Ga}_{0.8} \mathrm{As}$ quantum wells and 35 periods of $\mathrm{Al}_{0.92} \mathrm{Ga}_{0.08} \mathrm{As} / \mathrm{Al}_{0.16} \mathrm{Ga}_{0.84} \mathrm{As} p$-DBRs and 20 periods of $n$-DBRs, and was processed by selective oxidation. The oxide aperture size is $\sim 8 \times 8 \mu \mathrm{m}^{2}$. The threshold voltage is measured to be $1.58 \mathrm{~V}$. This is only $\sim 100 \mathrm{meV}$ above the photon energy. The differential resistance is $\sim 80 \Omega$ even for this small-aperture oxide device. The voltage drop is less than $2 \mathrm{~V}$ even when the output power is $3 \mathrm{~mW}$. The threshold current is about $1 \mathrm{~mA}$, and the slope efficiency is as high as $0.6 \mathrm{~W} / \mathrm{A}$. The wallplug efficiency is calculated to be $\sim 26 \%$, which is very high. These devices are also highly uniform across the entire 3" wafer. The total variation of the lasing wavelength is $5 \mathrm{~nm}$ around $844 \mathrm{~nm}$. This corresponds to a lasing wavelength uniformity of $\pm 0.3 \%$.

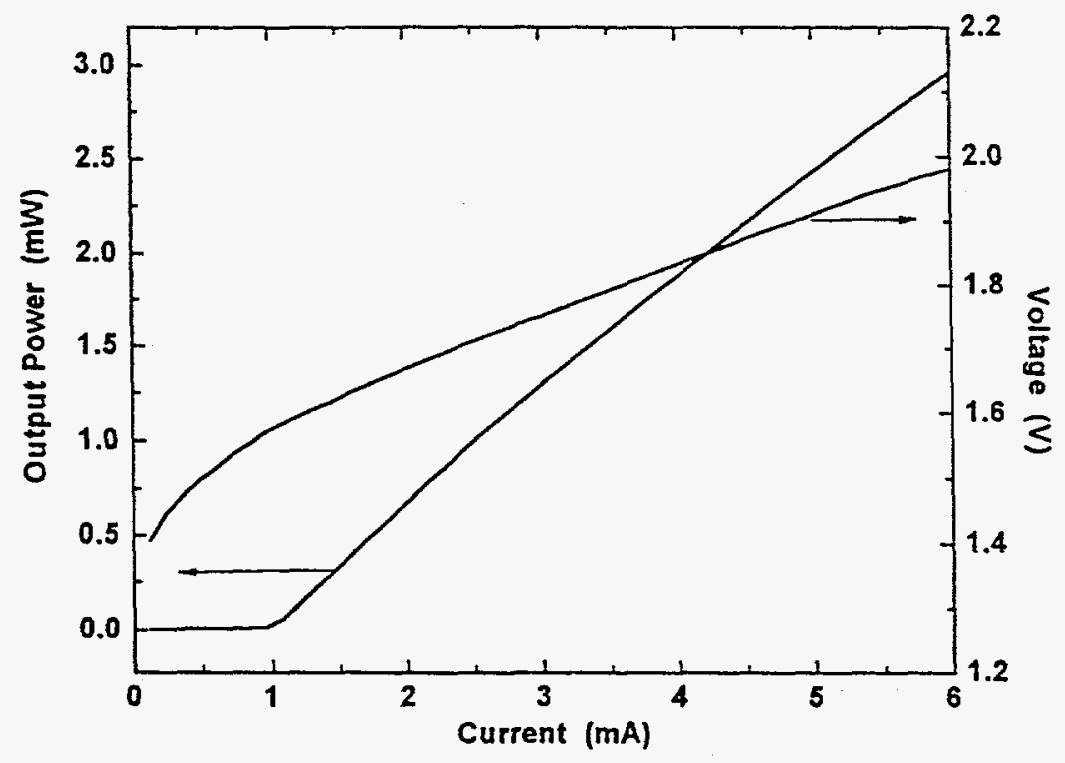

Fig. 11. L-I-V curves for an oxide-confined aperture VCSEL. The threshold voltage is $1.58 \mathrm{~V}$, and wallplug efficiency is $26 \%$.

\subsection{All-AlGaAs visible $(\sim 700 \mathrm{~nm})$ VCSELs}

Red VCSELs have attracted much attention for their potential applications in plastic optical fiber communications, bar-code readers, chemical sensing, laser printing and displays. To date, roomtemperature $\mathrm{CW}$ laser operation in the $650-700 \mathrm{~nm}$ wavelength regime has only been reported for AlGaInP materials. ${ }^{10}$ An alternative to this demanding material system is to use AlGaAs alloys for both the barriers 
and quantum wells. Work to date for AlGaAs-based red VCSELs has been either under pulsed operation with a low duty cycle $(<2.5 \%)$ or $\mathrm{CW}$ at low-temperature $\left(<-25^{\circ} \mathrm{C}\right) .^{11}$ We have demonstrated room temperature CW operation of all-AlGaAs $700 \mathrm{~nm}$ VCSELs for the first time. ${ }^{12}$

The VCSEL samples were grown on both (100) with $2^{\circ}$ off to (110) and (311)A GaAs substrates. Room temperature photoluminescence (PL) spectra from two calibration samples of the quantum well active layer suggests a 2.5-fold improvement of PL efficiency for the (311)A sample compared to the (100) sample. This can be attributed to reduced oxygen incorporation on (311)A surface and enhanced quantum efficiency due to a large heavy-hole effective mass along the growth direction in (311)A. ${ }^{12}$ The VCSEL structure consists of 55 -periods of $\mathrm{Si}$-doped $\mathrm{Al}_{0.96} \mathrm{Ga}_{0.04} \mathrm{As} / \mathrm{Al}_{0.4} \mathrm{Ga}_{0.6} \mathrm{As} n$-type bottom $\mathrm{DBRs}$, five $\mathrm{Al}_{0.24} \mathrm{Ga}_{0.76} \mathrm{As}(80 \AA) / \mathrm{Al}_{0.43} \mathrm{Ga}_{0.57} \mathrm{As}$ quantum wells placed at the center of a one-wave thick cavity, and 30 periods of $\mathrm{C}$-doped $\mathrm{Al}_{0.96} \mathrm{Ga}_{0.04} \mathrm{As} / \mathrm{Al}_{0.4} \mathrm{Ga}_{0.6} \mathrm{As} p$-type $\mathrm{DBRs}{ }^{12}$ The $\mathrm{Al}_{0.43} \mathrm{Ga}_{0.57} \mathrm{As}$ barrier layer was chòsen to provide enough confinement, but to avoid photo-generated carriers being trapped to the $\mathrm{X}$-valley through a non-radiative relaxation. The low index layers of the DBR pairs adjacent to the cavity were $\mathrm{Al}_{0.98} \mathrm{Ga}_{0.02} \mathrm{As}$, which was selectively oxidized to form a current aperture in the devices. Device characterization was performed from 5 to $50^{\circ} \mathrm{C}$.

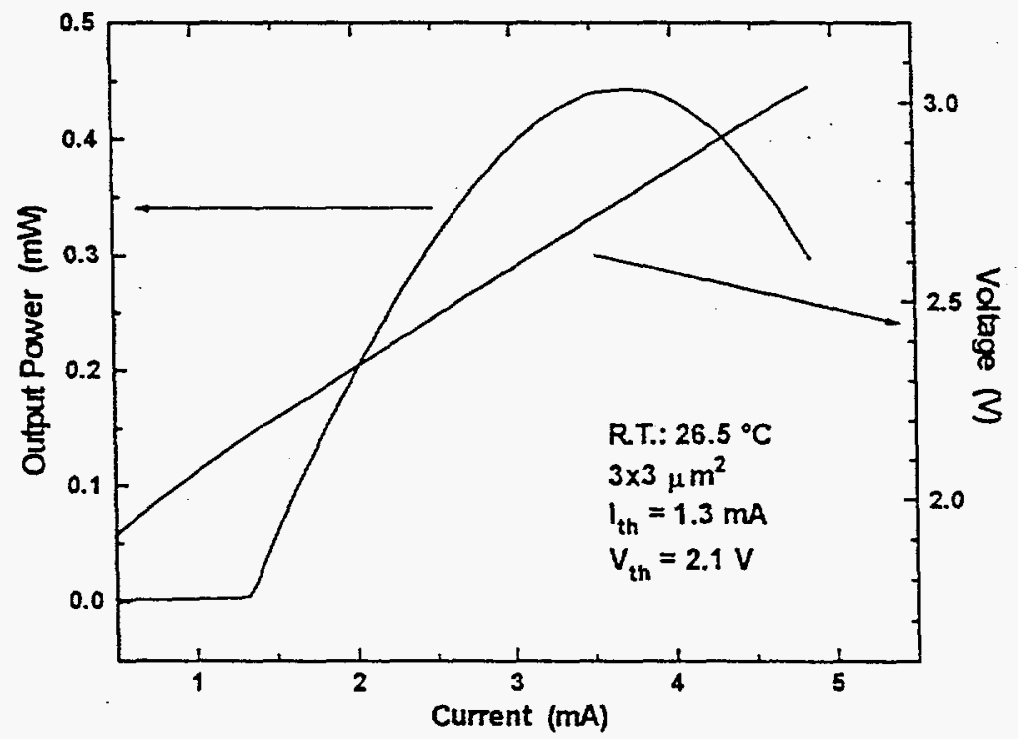

Fig. $12 \mathrm{~L}-\mathrm{I}$ characteristics of a $3 \times 3 \mu \mathrm{m}^{2}$ VCSEL at room temperature. The VCSEL emits at $703 \mathrm{~nm}$.

Shown in Fig. 12 is the CW output power detected by a calibrated Si photodiode and the voltage across the device as a function of operating current. The data were taken at room temperature $\left(26.5^{\circ} \mathrm{C}\right)$ for a $3 \mu \mathrm{m} \times 3 \mu \mathrm{m}$ device. Threshold current at room temperature was observed to be $1.3 \mathrm{~mA}$. The laser delivers nearly $0.5 \mathrm{~mW}$ of power, and the L-I rolls over due to thermal effects. The threshold voltage was $2.1 \mathrm{~V}$. The lasing was characterized by a clear speckle pattern from the laser and a sharp spectral feature at $703 \mathrm{~nm}$. The full width at the half maximum is as narrow as $1.4 \AA$, which is limited by the resolution of the monochromator.

\subsection{Low threshold current and threshold voltage $1.06 \mu \mathrm{m}$ VCSELs}

Compact semiconductor lasers with high beam quality emitting at $1.06 \mu \mathrm{m}$ have potential for applications currently dominated by Nd:YAG lasers. In addition, green lasers can be realized through second-harmonic generation of the $1.06 \mu \mathrm{m}$ lasers based on nonlinear optical effect of semiconductors. Furthermore, the study on $1.06 \mu \mathrm{m}$ lasers provides a pathway to a longer wavelength (e.g. $\sim 1.15 \mu \mathrm{m})$ 
which is transparent through $\mathrm{Si}$, and allows low-loss penetration through $\mathrm{Si}$ optical mounts or circuitry for free-space multiple-chip module interconnects, ${ }^{13}$ and utilization of Si diffractive optical elements for beam collimation and diffraction.

The VCSEL structure for $1.06 \mu \mathrm{m}$ wavelength consists of a one-wavelength thick cavity with three InGaAs (80 A)/GaAsP quantum wells placed in the center, a 35-period $n$-type bottom GaAs/Al $\mathrm{l}_{0.94} \mathrm{Ga}_{0.06} \mathrm{As}$ distributed Bragg reflector (DBR) mirror, and 18- to 25-period p-type top GaAs/A o.94 $\mathrm{Ga}_{0.06} \mathrm{As}$ DBR mirror. The thickness of the highly strained $(-2 \%) \mathrm{In}_{0.28} \mathrm{Ga}_{0.72} \mathrm{As}$ quantum well $(\mathrm{QW})$ was kept below the critical layer thickness limit and compensated by tensile strained $(\sim 0.7 \%) \mathrm{GaAs} s_{0.8} \mathrm{P}_{0.2}$ in the barrier layer. The thickness of the GaAsP barrier layer was chosen such that the net strain of the InGaAs/GaAsP heterostructure is zero. Three $80-\AA$ thick InGaAs QWs were embedded in the center of an AlGaAs cladding layer. Shown in Figure 13 is the room-temperature CW output power and the voltage as a function of operating current for devices with a 25-period top DBR. Threshold current for a $2.5 \times 2.5 \mu \mathrm{m}^{2}$ device is as low as $190 \mu \mathrm{A}$ as shown with the solid curve. This ultra-low threshold current can be attributed to a high differential gain in highly strained quantum wells. A larger device of $6 \times 6 \mu \mathrm{m}^{2}$ showed a threshold current of $0.58 \mathrm{~mA}$, as depicted with the dashed curve, and a threshold voltage as low as $1.255 \mathrm{~V}$, which is only 85 $\mathrm{meV}$ above the photon energy. With further optimization of the DBR design, the extrinsic voltage drop can be even lower (as low as $40 \mathrm{meV}$ ) as demonstrated previously. This low threshold voltage, indicative of very low DBR series resistance, is very important for the future datalink applications as the voltage standard of the driving circuit is moving to $1.5 \mathrm{~V}$. As shown in Fig. 13, for instance, the laser can emit with a reasonable amount of power at an operating voltage of $1.5 \mathrm{~V}$. A larger device of $22 \times 22 \mu \mathrm{m}^{2}$ with 20 top DBR periods contained multiple transverse modes, and delivered more than $4.5 \mathrm{~mW}$ of output power at $1.06 \mu \mathrm{m}$ wavelength. ${ }^{14}$

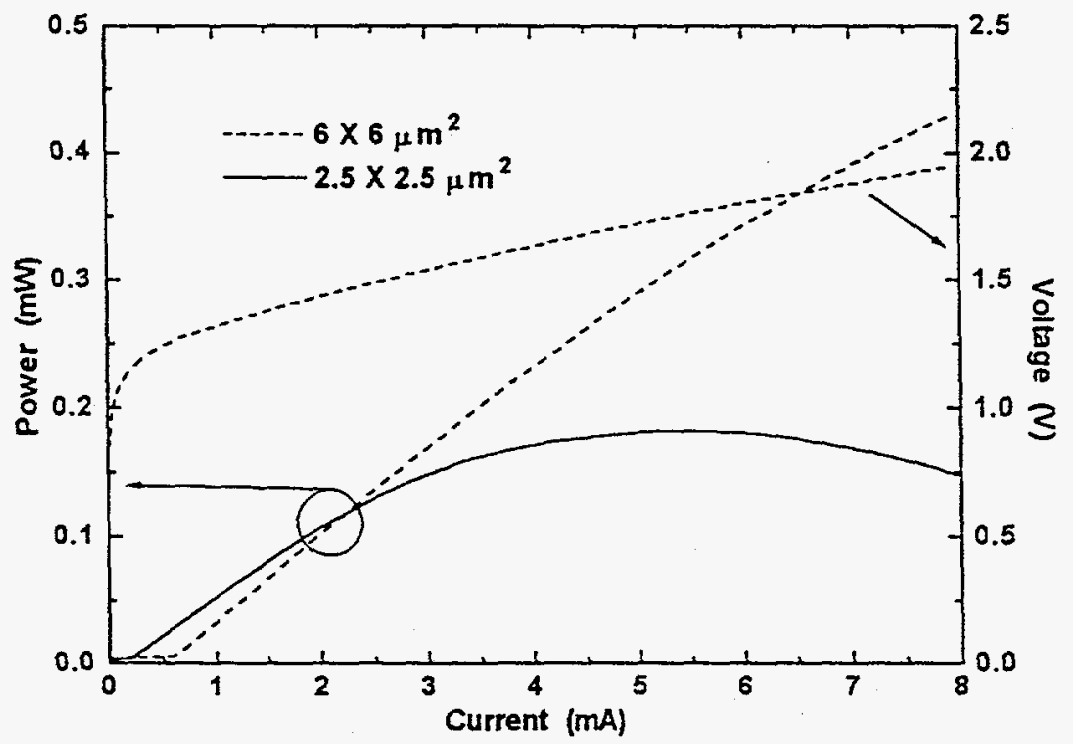

Fig. $13 \mathrm{~L}-\mathrm{I}-\mathrm{V}$ plots for oxide-confined $1.06 \mu \mathrm{m}$ VCSELs. The threshold current for a $2.5 \times 2.5 \mu \mathrm{m}^{2}$ is 190 $\mu \mathrm{A}$, and the threshold voltage for a $6 \times 6 \mu \mathrm{m}^{2}$ device is $1.255 \mathrm{~V}$.

\section{SUMMARY}

In summary, we have demonstrated an optimized MOVPE technique for VCSEL growth. Through an in situ growth-rate and composition calibration, extensive doping study, and proper mirror and active layer design of the devices, highly-uniform $( \pm 0.2 \%$ wavelength variation in nearly all of the 3 " wafer area), reproducible ( $\pm 0.3 \%$ over the course of 100 runs), high efficiency (wallplug of $26 \%$ ) and low threshold 
voltage (1.58 V) near-infrared $n$-up 850-nm VCSELs were achieved. In addition, we demonstrated the first room-temperature continuous-wave operation of 700-nm red VCSELs based on AlGaAs quantum wells. High-performance $1.06 \mu \mathrm{m}$ VCSELs were achieved with InGaAs/GaAsP strain-compensated quantum wells. The threshold current and threshold voltage are as low as $190 \mu \mathrm{A}$ and $1.255 \mathrm{~V}$, respectively. Our results show the potential of MOVPE as a very stable, reproducible, and uniform growth platform for VCSEL manufacturing.

\section{ACKNOWLEDGMENTS}

The authors acknowledge technical contributions from H. C. Chui, K. M. Geib, R. J. Hickman, and J. J. Banas. The research was performed at Sandia National Laboratories, a multiprogram laboratory operated by Sandia Corporation, a Lockheed Martin Company, for the United States Department of Energy under contract No. DE-AC04-94AL85000.

\section{REFERENCES}

1. See for example, Current Trends in Vertical Cavity Surface Emitting Lasers, Edited by T.P. Lee, World Scientific, Singapore, 1995.

2. W. G. Breiland and K. P. Killeen, "A virtual interface method for extracting growth rates and high temperature optical constants from thin semiconductor films using in situ normal incidence reflectance," J. Appl. Phys. 78, 6726 (1995).

3. H.Q. Hou, W.G. Breiland, B.E. Hammons, and H.C. Chui, "In situ growth rate measurements by normalincidence reflectance during MOVPE growth," Electrochemical Soc. Proc. 96-2, 27 (1996).

4. See a review, T. F. Kuech and J. M. Redwing, "Carbon doping in metalorganic vapor phase epitaxy," J. Cryst. Growth, 145, 382 (1994).

5. H. Q. Hou, B. E. Hammons, and H. C. Chui, "Carbon doping and etching of $\mathrm{Al}_{x} \mathrm{Ga}_{1-x} \mathrm{As}(0 \leq x \leq 1)$ with carbon tetrachloride in metalorganic vapor phase epitaxy," Appl. Phys. Lett. (1997).

6. N. Chand, T. Henderson, J. Klem, W. T. Masselink, R. Fisher, Y. -C. Chang, and H. Morkoc, "Comprehensive analysis of Si-doped $\mathrm{Al}_{x} \mathrm{Ga}_{1-x} \mathrm{As}(x=0$ to 1): theory and experiments," Phys. Rev. B30, 4481 (1984).

7. H. Q. Hou, K. L. Lear, B. E. Hammons, R. P. Schneider, Jr., "Silicon doping in $\mathrm{Al}_{x} \mathrm{Ga}_{1-x} \mathrm{As}(0 \leq x \leq 1)$ and reduction of series resistance of distributed Bragg reflectors," (to be submitted).

8. H. Q. Hou, H. C. Chui, K. D. Choquette, B.E. Hammons, W. G. Breiland, and K. M. Geib, "Highly uniform and reproducible vertical-cavity surface emitting lasers grown by metalorganic vapor phase epitaxy with reflectometer," IEEE Photon. Technol. Lett. 81285 (1996).

9. K. D. Choquette, K. L. Lear, R. P. Schneider, Jr., K. M. Geib, J. J. Figiel, and R. Hull, "Fabrication and performance of selectively oxidized vertical-cavity lasers IEEE Photon. Technol. Lett. 7, 1237 (1995).

10. M. H. Crawford, R. P. Schneider, Jr., K. D. Choquette, and K. L. Lear, "Temperature-dependent characteristics and single-mode performance of AlGaInP-based 670-690-nm vertical-cavity surface-emitting lasers" IEEE Photon. Technol. Lett. 7, 724 (1995).

11. B. Tell, K. F. Brown-Goebeler, and R. E. Leibenguth, "Low temperature continuous operation of vertical-cavity surface emitting lasers with wavelength below $700 \mathrm{~nm}$," IEEE Photon. Technol. Lett. 5, 637 (1993).

12. H. Q. Hou, M. H. Crawford, R. J. Hickman, and B. E. Hammons, "Room-temperature continuous-wave operation of all-AlGaAs visible $(\sim 700 \mathrm{~nm})$ vertical-cavity surface emitting lasers," Electron. Lett. 32, 1986 (1996).

13. R. F. Carson, M. L. Lovejoy, K. L. Lear, M. E. Warren, O. Blum, P. K. Seigal, D. C. Craft, S. P. Kilcoyne, and G. A. Patrizi, Proc. of IEEE Lasers and Electro-Optics Societv 1995 Annual Meeting, San Francisco, CA, USA. 2,125 (1995).

14. H. Q. Hou, K. D. Choquette, K. M. Geib, and B. E. Hammons, "High-performance $1.06 \mu$ m selectively oxidized vertical-cavity surface-emitting lasers using InGaAs/GaAsP strain-compensated quantum wells," IEEE Photon. Tech. Lett. (1997). 